Georges Güntert

\title{
Entusiasmo y crítica: Gustav Siebenmann, lector de la obra poética de Federico García Lorca
}

Resumen: Una de las principales líneas de investigación de Gustav Siebenmann ha sido la obra de García Lorca. Ya antes de publicar Die moderne Lyrik in Spanien (1965), Siebenmann había analizado con gran entusiasmo algunos aspectos del lenguaje poético del granadino, cuya obra siguió estudiando a lo largo de su carrera, dedicándole más de veinte trabajos. En este ensayo se intenta describir su acercamiento crítico a los diferentes estilos líricos de Lorca, y sugerir, cuando nos ha parecido oportuno, nuevas lecturas de la poesía lorquiana, no siempre fácilmente inteligible.

DOI 10.1515/ibero-2014-0025

Huelga recordar que la obra de Federico García Lorca ha sido uno de los campos de investigación predilectos del profesor Siebenmann. Lo demuestran sus numerosas publicaciones al respecto (¡entre libros, artículos y reseñas suman más de veinte!) y el espacio que reserva a este poeta ya en su tesis de habilitación, Die moderne Lyrik in Spanien (1965), cuya traducción española, publicada por Gredos, salió a la luz en 1973. En la versión original de este panorama histórico, Lorca aparece retratado como representante de dos diferentes estilos, a saber, del neopopularismo y del surrealismo, y se le dedican, en conjunto, más de quince páginas: son muchas, si se comparan con las tres referidas a Luis Cernuda, a quien se recuerda únicamente entre los testigos de la "poesía pura"; o con las siete consagradas a Jorge Guillén. En la edición española del libro, la presencia de Lorca aumenta considerablemente. Debido a la inserción de nuevos poemas comentados, se le conceden ahora treinta y tres páginas, frente a las cuatro de Cernuda y a las diez de Jorge Guillén, poetas que, a mi modo de ver, no son inferiores al autor del Romancero gitano.

¿Cómo se explica esta predilección por Federico García Lorca o, si nos atenemos al canon actual, esta llamativa desproporción? (En cuanto al canon, podríamos consultar la Historia de la literatura española dirigida por Francisco Rico, donde Lorca, Cernuda y Guillén ocupan más o menos el mismo espacio).

Georges Güntert: Bahnweg 4, CH-8700 Küsnacht, E-Mail: geoguent@bluewin.ch 
Para justificar la preferencia del profesor Siebenmann por los estudios lorquianos, podríamos comenzar por destacar el hecho de que su libro está dirigido a un público germano. ${ }^{1}$ En Alemania, Suiza y Austria, ya desde los años de la posguerra, Lorca gozaba de una fama extraordinaria, gracias, sobre todo, a sus éxitos teatrales: Bodas de sangre (Bluthochzeit) se estrenó en Zúrich en 1944; Yerma, en Berna en 1946; La casa de Bernarda Alba, en Basilea al año siguiente; aún hoy, Lorca es el autor español más representado en los teatros de lengua alemana. ${ }^{2}$ Pero el particular enfoque cultural del libro Die moderne Lyrik in Spanien no puede explicar todo aquel entusiasmo y cuidado filológico, tanto más cuanto que Siebenmann, en la versión española de su estudio, continúa sosteniendo su tesis acerca de la superioridad del granadino con respecto a otros poetas de la misma generación. Es allí donde encontramos la afirmación de que "Federico García Lorca [...] sobresale con su fama, abierta a todo lo ancho del mundo, por encima de la generación entera de los años veinte” (Siebenmann 1973: 290). Ya que el argumento es el de la fama del poeta, el de su universal renombre, podríamos suponer que Siebenmann consideraba no solo la calidad de la poesía de Lorca, sino también su enorme popularidad, su mito, y es este un aspecto que un historiador de la literatura no puede pasar por alto. ${ }^{3}$ Lorca fue, en su vida, un personaje de una simpatía irresistible, un talento múltiple, pintor, músico, poeta - "nadie con más naturalidad poeta”, decía de él Jorge Guillén (1973: LV)-, y no extraña que el crimen de Víznar se haya cargado de un trágico simbolismo: el del asesinato del poeta por parte de una sociedad intolerante, vengativa, brutal. Con todo, después de evocar estos hechos y los rasgos salientes de la personalidad del poeta, Siebenmann opina que "incluso cuando se hace abstracción de tales circunstancias, nos encontramos en la obra lírica de Lorca con la más espontánea, originaria calidad artística de esa época altamente poética” (1973: 290). Dicho esto, se ve claramente que nuestro colega pone a Lorca por encima de sus contemporáneos y que lo prefiere a ellos por su originalidad e inagotable vena creadora. "Weil er ein großer Dichter war": así, con la famosa frase de Luis Buñuel sobre los verdaderos motivos que llevaron al asesinato de Lorca, comenzaba un artículo de periódico publicado con motivo del centenario del nacimiento

1 En el mundo germano, en efecto, el caso de Siebenmann está lejos de constituir una excepción. En un recién publicado manual de literatura destinado a los hispanistas alemanes, el responsable de la sección "Poesía del siglo XX", Manfred Lentzen, elige a Lorca como principal representante de la generación del 27 (cfr. Rivero Iglesias 2014).

2 Para más detalles, véase Rudin 1997.

3 Escribe el editor de la Obra completa, Miguel García-Posada, en su "Introducción general”: "La difusión universal de la obra lorquiana no ha dejado de crecer desde 1936. Solo Cervantes, entre los escritores de la lengua, ha conocido una expansión semejante” (2008: 29). 
del poeta (Siebenmann 1998: 67); y otro trabajo suyo, incluido en el volumen de los Ensayos, se llama “Lorca: ein Versuch, seine Größe zu begründen” (Siebenmann 1989: 226).

Siebenmann dirige su mirada crítica, en primer lugar, hacia el estilo neopopularista de Lorca, esto es, hacia lo realizado entre 1921 y los años del Romancero gitano. No dedica sino pocas líneas a su obra juvenil, el Libro de poemas, que le parece de interés solo "si examinado a posteriori", en cuanto ofrece "indicios de la gran poesía” que vendrá después (Siebenmann 1973: 292). Creo, no obstante, que, para comprender mejor el carácter novedoso del Poema del cante jondo y de las colecciones sucesivas, valdría la pena comparar el primer y el segundo modo de poetizar de Lorca e insistir en las principales diferencias de estilo. Me anima a ello la actitud positiva de la crítica más reciente, la de Miguel García-Posada, por ejemplo, quien caracteriza la obra juvenil de Lorca con estas palabras:

El Libro de poemas contiene [...] poemas de altísima calidad, que no suelen ser frecuentes en los primeros libros. Abundan los momentos muy felices en la mayoría de las composiciones y, en todo caso, el poeta demuestra siempre su absoluta conciencia de la composición y el diseño, de la contención en el momento justo y del clamor también en el momento adecuado. No hay vacilaciones técnicas de aprendiz (2008: I, 131-132).

Los poemas juveniles, más bien extensos, tienen a menudo un carácter narrativo: son narraciones en verso de asunto imaginario, baladas, algunas veces, o fábulas con actores zoomorfos (las cigarras, las mariposas, el lagarto viejo, el caracol, las ranas, la hormiga herida) que representan ideas o actitudes morales de cierta importancia para la biografía espiritual del poeta: la crítica a la mentalidad burguesa y el riesgo que corre quien se entrega a la aventura poética; o bien la frustración de quien no consigue ni acceder a la vida de las pasiones ni cantar. La hostilidad con que la sociedad mira a los artistas y, por tanto, la conciencia del poeta de su diversidad ya se intuyen allí perfectamente: véase, en especial, el poema "Los encuentros de un caracol aventurero" (García Lorca 2008: I, 169174). Otras veces se nos invita a contemplar paisajes otoñales, a la manera de Jammes o de Juan Ramón, sin que falten del todo los ecos machadianos, advertidos también por nuestro colega (Siebenmann 1973: 292). La metáfora quizás más frecuente, con más de cincuenta ocurrencias, es la de “estrella(s)”, que evoca la inalcanzable luz del más allá, en un sentido no tanto religioso cuanto estético. La adopción de esta metáfora algunas veces tiene que ver con la falta de inspiración que engendra melancolía: "Hoy siento en el corazón / un vago temblor de estrellas, / pero mi senda se pierde / en el alma de la niebla” (García Lorca 2008: I, 174); otras, con el conflicto entre trascendencia e inmanentismo: “¿Cómo son las estrellas, aquí? -Hijo mío, igual que en el cielo” (García Lorca 2008: I, 201). Donde el rechazo de lo trascendente se hace explícito es en el poema "Mar", que 
acaba con los versos: “... Y el hombre miserable / es un ángel caído. / La tierra es el probable / paraíso perdido” (García Lorca 2008: I, 275).

\section{El neopopularismo: desde El poema del cante jondo al Romancero gitano}

La verdadera novedad del Poema del cante jondo -compuesto en solo quince días en el mes de noviembre de 1921-, se manifiesta, a mi modo de ver, en una mayor sensibilidad por la disposición espacial del texto. No me refiero al espacio representado, sino al espacio de la representación: a la disposición tipográfica de los versos en la página. Los nuevos poemas son breves y se organizan a modo de dibujos, apoyándose en las técnicas espaciales del paralelismo vertical (la anáfora), de la simetría y del contraste. La sencillez del discurso es herencia de la tradición popular, que guía la mano al creador de estos versos, pero su disposición, su tono y, sobre todo, su carácter autoreflexivo no dejan de ser modernos. Procede de la tradición también otro rasgo novedoso de estos poemas: la ausencia, o casi, del yo biográfico y, por consiguiente, la falta de todo sentimentalismo. El poema juvenil "Cigarra”, de 1918, por citar un ejemplo de la primera manera, empieza con estos sugestivos versos: “¡Cigarra! / ¡Dichosa tú!, / que sobre el lecho de tierra / mueres borracha de luz”, pero acaba con un comentario alegórico y una nota subjetiva: "Sea mi corazón cigarra / sobre los campos divinos. / Que muera cantando lento / por el cielo azul herido” (García Lorca 2008: I, 182-183). En el Poema del cante jondo, en cambio, cuando surge una primera persona -por ejemplo, en este verso puesto entre paréntesis y repetido a manera de un estribillo: "Dejadme en este campo / llorando" (García Lorca 2008: I, 310)-, podemos estar seguros de que ese "yo" no es sino una voz humana que interpreta el paisaje desde dentro. Ahora bien, tanto la conciencia de la espacialidad del discurso como la renuncia al sentimentalismo confirman la tendencia hacia una mayor autonomía del objeto artístico, de acuerdo con el gusto estético de la vanguardia de los años veinte. Pueden encontrarse antecedentes entre los simpatizantes de la poesía creacionista (Vicente Huidobro, Gerardo Diego), quienes imitaban los experimentos tipográficos de los poetas franceses, de Max Jacob o Apollinaire, sin ir más lejos.

Es posible destacar otra característica en las composiciones del Poema del cante jondo: su componente lúdico, la facilidad de la inspiración, el astro propio de un poeta que "tiene ángel”, cuando no se deja llevar por el "duende”, cuya presencia, desde luego, tampoco facilita la interpretación. Pues, ¿qué significan los Poemas del cante jondo cuando no se reducen a ser alegorías de los instrumen- 
tos del cante y de sus formas estróficas (como ocurre, de hecho, en "Adivinanza de la guitarra”, "Las seis cuerdas”, “Crótalo”, "La soleá”, "Saeta”, "El paso de la siguiriya”, etc.)? ¿Qué es lo que quiere expresar ese Lorca andaluz, cuando se identifica con el dolor de su pueblo? ¿Quiere unirse totalmente a su gente hasta aniquilar su personalidad o sigue transmitiéndonos un mensaje poético individual? ¿Cuál es el sentido de su poesía neopopularista, si es que lo tiene? Jorge Guillén recuerda a este propósito un comentario irónico de Salvador Dalí, quien, después de un recital del Romancero gitano hecho por Lorca, se permitió exclamar: "Parece que tiene argumento, ipero no lo tiene!" (Guillén 1973: XLVIII). Siebenmann no desatiende la delicada cuestión de los significados, pero es consciente de la enorme dificultad que su análisis comporta, ya que escribe: "La poesía de Lorca, tan fuertemente apoyada en lo intuitivo, se muestra como difícilmente sistematizable. Pero en todo momento queda patente su maestría artística” (Siebenmann 1973: 315). En otro lugar de su estudio, interpreta la actitud de Lorca frente a la vida y al arte como un desafío de tipo existencialista, o casi: el poeta, amenazado por la muerte, tiene "un sentimiento agónico de la existencia” y reacciona "heroicamente" a ello, con su voluntad creadora. Concluye afirmando que, si existe un motivo dominante en estos poemas, es el de "una expectante tristeza” (Siebenmann 1973: 295). Angustia de la muerte, por tanto, y “ein Gefühl harrender Trauer” (Siebenmann 1965: 188). No me opongo a esta lectura: solo me parece aún bastante general, y es que la característica principal destacada por el crítico, el desafío a la transitoriedad de la vida, resulta ser propia de muchos artistas modernos. Desde mi punto de vista, si tuviese que profundizar en el análisis del sentido de la obra poética de Lorca, intentaría deducirlo de los mismos textos, aun sabiéndolos reacios a la elucidación.

Voy a intentarlo en el limitado espacio que este estudio me concede. Ya el poema que sirve de pórtico, la "Baladilla de los tres ríos", con su comparación entre los dos ríos de Granada, Darro y Genil, y el río mayor de Sevilla, el Guadalquivir, deja entrever uno de los motivos centrales de la poesía lorquiana, el del deseo irrealizable y la consecuente frustración, puesto que reza: "Para los barcos de vela / Sevilla tiene un camino; / por el agua de Granada / solo reman los suspiros" (García Lorca 2008: I, 295). El contraste entre ambas ciudades se acentúa cuando a la verticalidad y dinamismo de Sevilla se les oponen el sentimiento de la pasada grandeza y el vicio autocontemplativo de la ciudad natal de Lorca: "Guadalquivir, alta torre / y viento en los naranjales. / Dauro y Genil, torrecillas / muertas sobre los estanques". ${ }^{4}$ En una de sus conferencias del período 1926-1928,

4 "Dauro" es el nombre latino de uno de los ríos granadinos: el "Darro". Lorca, algunas veces, prefiere la forma culta a la forma común, por ejemplo, en su poema "Elegía a Doña Juana la Loca" 
titulada "Paraíso cerrado para muchos, jardines abiertos para pocos", Lorca define a Granada como una ciudad "ceñida por sus sierras", sin más salida que "su alto puerto natural de estrellas", pero "apta para el sueño y el ensueño"; y concluye su comentario con la comparación: "Granada es como la narración de lo que ya pasó en Sevilla” (García Lorca 2008: VI, 264).

Para describir el valor semántico de este y otros poemas de los años veinte, es aconsejable recurrir a un lenguaje crítico más abstracto: se nos ofrecen, en las composiciones del Poema del cante jondo, visiones de paisajes y modulaciones musicales -y adviértase que estas pueden ser metáfora de aquellas-, rítmicos paisajes, decía, y ondulaciones musicales que sugieren ambos, a través de una creciente tensión, el deseo o el sueño irrealizable. Asimismo, se nos habla de la sed, la de los campos en sequía, los cuales, no hallando refrigerio, expresan un sufrimiento análogo al deseo que no encuentra satisfacción. Todo esto implica frustración, pena, conciencia del fracaso, no importa si tales condiciones se atribuyen a la tierra andaluza o al propio poeta (a quien, sin embargo, no se nombra casi nunca). En sus conferencias sobre "El cante jondo" y la "Arquitectura del cante jondo", Lorca utiliza a menudo el símil "canto andaluz igual a paisaje', diciendo, por ejemplo, "la siguiriya gitana me había evocado a mí (lírico incurable) un camino sin fin, sin encrucijadas"; o bien: "la siguiriya gitana comienza por un grito terrible, un grito que divide el paisaje en dos hemisferios ideales" (García Lorca 2008: VI, 229). Varios poemas, de hecho, sugieren la idea de un grito que no consigue articularse, un grito de dolor sofocado. Así ocurre en "Paisaje": "Los olivos / están cargados / de gritos". Esta incapacidad de liberarse crea efectos de cansancio, tedio y desesperanza, perceptibles, por ejemplo, en "Pueblo": "veletas girando. / Eternamente girando. / Oh pueblo perdido / en la Andalucía del llanto". Algunas veces, no obstante, el poema mismo se hace "grito" o, dicho con otra imagen análoga, "puñal": esto ocurre cuando se insiste en el modo performativo del canto, en la tensión que finalmente estalla con violencia e hiere. El puñal o el grito, sugeridos asimismo por el género musical de la "saeta", pueden referirse bien al enunciado, bien a la enunciación (por ejemplo, en el poema que se titula “¡Ay!”), lo cual confirma, una vez más, el tenor autorreflexivo de estos textos.

Los siguientes versos, Suites (1920-23) -siguientes en el orden de las Obras, no en cuanto a su fecha de publicación $-{ }^{5}$ aportan algunas novedades, sobre todo en el nivel imaginativo, si bien las técnicas de conjugar las formas de la tradición y las conquistas técnicas de la vanguardia continúan siendo las mismas que en el

(García Lorca 2008: I, 181). Pero en la antología Poesía española contemporánea, de Gerardo Diego, aparece la forma "Darro" (Diego 1968: 410).

5 Una parte de las Suites fue publicada en 1935, en el libro Primeras canciones, pero la mayoría de estos poemas apareció originalmente en revistas. 
Poema de cante jondo. Llama la atención la originalidad de la imagen del "remanso", que en el mundo poético de Lorca puede ser de agua, de aire, de pupila, de boca, de silencio, etc., en cuanto atrae el deseo e invita a la meditación o al recuerdo. La suite de los "remansos" sigue a la de los "espejos", con la que tiene mucho en común: el "agua estancada” puede servir de "espejo”, y ambos son metáforas de la conciencia poética. Existe un fragmento en prosa centrado en el motivo del "remanso", escrito hacia 1921, que facilita la comprensión de este género de búsqueda poética. En él, Lorca evoca una experiencia de adolescente en la que una imagen lejana, inasequible ("el pájaro de oro"), se reflejó en el espejo del agua, y por tanto en el de su alma, convertida en visión interior. Ahora bien, es curioso que el yo-poético asocie esa visión a la de las “estrellas”, imagen tradicional de lo trascendente, en un momento en que le interesaba cada vez más la vida terrenal. Es como si la experiencia marcase otra etapa en el camino del poeta hacia una concepción inmanente del mundo:

[...] Bajo los mimbres picudos, junto a la lengua del agua, yo siento cómo toda la tarde abierta hunde mansamente con su peso la verde lámina del remanso, cómo las ráfagas de silencio ponen frío el asombrado cristal de mis ojos.

Los primeros días me turbó el espléndido espectáculo de los reflejos, las alamedas caídas que se ponen salomónicas al menor suspiro del agua, los zarzales y los juncos que se rizan como una tela de monja.

Pero yo no observé que mi alma se iba convirtiendo en prisma, que mi alma se llenaba de inmensas perspectivas y de fantasmas temblorosos. Una tarde miraba fijamente la verdura movible de las ondas y pude contemplar cómo un extraño pájaro de oro se curvaba sobre las ondas de un chopo reflejado; miré a la copla real que estaba inundada de sol poniente y solo los invisibles pájaros del viento jugaban entre las hojas; el pájaro de oro había desaparecido.

Una frescura maravillosa invadió todo mi cuerpo, envuelto en las últimas hebras de la cabellera crepuscular y una inmensa avenida luminosa atravesaba mi corazón. ¿Es posible? Mi alma hace excursiones a las ondas en vez de visitar las estrellas? (García Lorca 2008: I, 484-485). ${ }^{6}$

Canciones (1921-1924), compuesto de once distintas secciones, es un libro más variado, sobre todo desde el punto de vista formal, y es también un libro más irónico. Vuelve a proponer, en "Las canciones para niños”, algunos motivos del libro juvenil, aunque solo sea para ironizar sobre ellos. En la sección "Juegos", dedicada a Buñuel, con su divertida "Canción del mariquita” y con “Árbol de

6 Las cursivas son nuestras. 
canción”, un poema escrito para Ana María Dalí, el poeta vuelve a la temática del deseo imposible, pero lo hace ahora con gracia, sin poner énfasis en el sufrimiento: "Caña de voz y gesto, / una vez y otra vez / tiembla sin esperanza / en el aire de ayer. / La niña suspirando / lo quería coger; / pero llegaba siempre / un minuto después” (García Lorca 2008: I, 545). A pesar de la afinidad temática, el tono es leve, jocoso, denotando ahora, sobre todo, virtuosismo. En “Andaluzas”, finalmente, donde encontramos algunas obritas de rara perfección, se anticipan las situaciones del Romancero gitano, la del jinete que no llega a su meta o la del viento que, igual que un sátiro, persigue a una muchacha, situaciones vinculadas al motivo del deseo frustrado o del viaje sin realizar. Como ejemplo podemos citar un fragmento de la sugerente "Canción de jinete", una de las más hermosas composiciones de este libro, que Lorca no olvidó incluir entre los poemas seleccionados en la antología Poesía española contemporánea de Gerardo Diego: "Córdoba. / Lejana y sola. / Jaca negra, luna grande, / y aceitunas en mi alforja. / Aunque sepa los caminos / yo nunca llegaré a Córdoba.” [...] “¡Ay qué camino tan largo! / ¡Ay mi jaca valerosa! / ¡Ay que la muerte me espera, / antes de llegar a Córdoba!” (García Lorca 2008: I, 526). Son motivos tradicionales, ciertamente, pero reinterpretados con la sensibilidad de un poeta moderno como lo era Lorca.

El Romancero gitano sí que ofrece elementos innovadores. En cuanto romances, los nuevos poemas se vuelven más narrativos, incluso dramáticos. Presentan conflictos: la pasión, con sus consecuencias destructoras, choca aquí con las normas sociales propias de una sociedad represiva que persigue al gitano y condena a la mujer desobediente, enamorada. Es verdad que esto no ocurre en todas las composiciones, pero sí en su gran mayoría: baste con recordar el "Romance sonámbulo", el "Romance de la pena negra”, "La casada infiel", "Muerto de amor” y el "Romance de la Guardia Civil española”. En otras ocasiones, cuando la protagonista es una mujer, aparecen persiguiéndola las típicas figuras del erotismo: el viento, el jinete o, por metonimia, su caballo: así ocurre en "Preciosa y el aire” y en los sueños eróticos de "La monja gitana”. La mayoría de estos poemas exalta la violencia de la pasión frente al poder represivo de la comunidad, y es esta una de las temáticas principales en la obra del último Lorca, especialmente en sus dramas. Lorca es un poeta capaz de inventar situaciones cada vez nuevas, pero, si analizamos los significados que estas proponen, no podemos sino comprobar cierta monotonía temática. Sabido es que el Romancero gitano es uno de los mayores éxitos literarios de todos los tiempos. Pero no hay que desatender el declarado disentimiento de algunos críticos de renombre, incluso de entre los más próximos a Lorca. Así, Salvador Dalí escribió a Federico a propósito de su nuevo libro: “Tu poesía actual va de lleno dentro de lo tradicional, en ella advierto la sustancia poética más gorda que ha existido, pero 
ligada en absoluto a las normas de la poesía antigua, incapaz de emocionarnos, ni de satisfacer nuestros deseos actuales"; y Buñuel, por su parte, confesó a Dalí que el libro le parecía "malo, muy malo” (García-Posada 2008: I, 101).

Pues bien, de entre los dieciocho poemas del Romancero gitano Siebenmann interpreta el segundo, "Preciosa y el aire". En su lectura subraya los puntos de contacto entre la tradición popular y la modernidad de Lorca: señala, por ende, que el papel de "peligroso violador" atribuido al viento está bien documentado en la tradición folclórica y lo demuestra con una copla, extraída de los Cantos populares españoles de Francisco Rodríguez Marín, que reza: "No vayas solita al campo / cuando sopla el aire recio; / porque las niñas son flores / que hasta las deshoja el viento" (Rodríguez Marín 1981: IV, 75). Asimismo, una de las Canciones del propio Lorca, la que empieza con el estribillo "Arbolé arbolé / seco y verdé", presenta al viento como un tempestuoso amante que "prende por la cintura" a "la niña de bello rostro" mientras está cogiendo aceitunas (García Lorca 2008: 528). Pero, según Siebenmann, en "Preciosa y el aire” el poeta va más lejos, ya que convierte "lo estático del símbolo erótico" en drama. Al insistir en el poder agente del viento y al compararlo con un sátiro, consigue sugerir "todo lo sacro y terrible de una fuerza sobrenatural avasalladora”, creando un mito que es al mismo tiempo un fenómeno natural (Siebenmann 1973: 314). Siebenmann no ignora la existencia de mitos eólicos en la antigüedad, el de Bóreas como raptor de Oreithyía, por ejemplo, mencionado por Platón en el Phaidros; no obstante, está convencido de presenciar un mito nuevo, propiamente lorquiano, de los que el poeta sabrá evocar en sus tragedias (Siebenmann 1989: 242, n. 43).

La misma extraña "mezcla de lo erótico con lo sacro" anima la trilogía de los arcángeles, sobre la que Siebenmann no quiso expresarse. Si damos aquí una ojeada crítica a estos poemas, es para observar de cerca las técnicas empleadas por el autor del Romancero gitano. "San Miguel”, "San Rafael” y "San Gabriel”: así se titulan los tres romances dedicados a las principales ciudades andaluzas. Son poemas de tema folclórico y religioso, al menos aparentemente; en realidad, sirven al poeta de pretexto para dar rienda suelta a su humorismo y sus fantasías eróticas. Una belleza algo ambigua caracteriza al San Miguel granadino: su estatua de joven efebo, "fragante de agua colonia", enseña sus "bellos muslos" desde la torre de la ermita, situada en lo alto del Sacro Monte, donde se celebra una romería en su honor. La atmósfera está preñada de erotismo: las manolas gitanas, paseando entre "altos caballeros y damas de triste porte", comen semillas en la calle y ostentan sus formas redondas, "los culos grandes y ocultos / como planetas de cobre”, mientras los fieles se reúnen para asistir a misa -una pintura a la manera de Fernando Botero-. Lorca no deja de relacionar esta mezcla de conmemoración religiosa y feria popular con la vida de la naturaleza, hablando ya del cielo de "mulos blancos" - de nubes, supongo, ya que San Miguel se 
celebra a finales de septiembre-, ya del lejano mar "que baila por la playa, / un poema de balcones” (García Lorca 2008: II, 157-158). ${ }^{7}$ El erotismo lorquiano, una vez más, tiene sus lejanas correspondencias en el mundo cósmico.

El "San Gabriel” sevillano, "un bello niño de junco, / anchos hombros, fino talle, / piel de nocturna manzana", es, sin duda alguna, el más hermoso de los tres arcángeles. Su gran momento, la Anunciación a la Virgen -representada en el retablo de la Capilla de la Encarnación, dentro de la Catedral-, se describe como un encuentro erótico, en el que la intervención del Espíritu Santo sobra, ya que la Virgen se embelesa con el ángel: “¡Ay San Gabriel de mis ojos! / ¡Gabrielillo

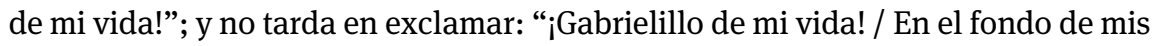
pechos / ya nace la leche tibia” (García Lorca 2008: II, 161). Se comprende ahora por qué a este ángel seductor se le llama, ya desde la introducción, "domador de palomillas". El milagro es obra de su sex appeal; el misterio religioso queda reducido a fenómeno erótico. Así, el soplo divino de los evangelios se ha materializado en el eros, símbolo de fuerza vital y de inspiración poética.

De los tres, el más enigmático es el ángel custodio de Córdoba, San Rafael, cuyo poema está inspirado en una estatua que se halla en medio del Puente Romano. La ciudad evocada por el poeta es una Córdoba mítica: romana, sobre todo, pero influida también por las grandes religiones de la Edad Media, islam, judaísmo y cristianismo, las cuales, adviértase, veneran todas a este arcángel. El episodio bíblico de Rafael y Tobías lleva al poeta a centrarse en la imagen del pez -la estatua del Puente Romano sujeta, de hecho, un animal semejante-: "Un solo pez en el agua / que a las dos Córdobas junta” (García Lorca 2008: II, 159). Las dos Córdobas son "la de juncos", al sur del puente, donde predomina la naturaleza, y "la de arquitectura", al norte, famosa por sus monumentos: naturaleza y arte, por tanto. A ambas partes el pez les sirve de "lección y equilibrio", mientras los niños, "aprendices de Tobías", le dirigen la irónica pregunta de "si quiere flores de vino / o saltos de media luna”, esto es, si prefiere algo cristiano o algo musulmán. Los niños, los juncos, el pez: en estas tres figuras de la vida, de la elegancia flexible, "juncal", y de la sabiduría, se apoya este originalísimo romance, lleno de sugerencias míticas.

7 Es cierto que los "mulos blancos" del cielo, en este romance, remiten a los “mulos y sombras de mulos" de la sierra, poco antes mencionados, y que ambos significantes resuenan en los "bellos muslos" del arcángel Miguel, evocados en los vv. 19-20. 


\section{Lorca y el surrealismo}

En lo siguiente trataremos de elucidar brevemente la posición surrealista de García Lorca concordando con Gustav Siebenmann en que Lorca no es lo que se dice un surrealista ortodoxo a la manera de André Breton o de Vicente Aleixandre. Siebenmann lo demuestra mediante el análisis de un poema del libro Poeta en Nueva York, "Niña ahogada en el pozo", que se abre con una imagen recurrente en textos anteriores de Lorca, desde Canciones ("Al estanque se le ha muerto / hoy una niña de agua”) hasta el "Romance sonámbulo”. La imagen de la niña ahogada expresa, una vez más, la ilusión truncada, la imposibilidad de vivir y la omnipresencia de la muerte, que se traduce, en este poema, en la imagen obsesiva del "agua que no desemboca” (García Lorca 2008: II, 275). Para Siebenmann, es importante la coherencia formal de este texto, que, según pone de relieve, "denota adhesión a un principio artístico que sin orden no se logra" (Siebenmann 1973: 341). Su análisis detallado de las estrofas le permite descubrir "una ordenación artísticamente eficaz", que es todo lo contrario del automatismo.

Lorca, de hecho, no concibe su poesía como una expresión onírica (Breton) ni como un canto a la creación total (Aleixandre). Lo que sí se advierte en su obra, ya desde muy temprano, es una búsqueda frenética de la imagen original, que lo lleva a inventar constelaciones de gusto protosurrealista, como cuando escribe en Primeras canciones, esto es, en 1922, confundiendo los espacios de los elementos: "El bosque centenario / penetra en la ciudad, / pero el bosque está dentro / del mar" (García Lorca 2008: I, 428); o cuando dice en la sección "Nocturnos de la ventana”, de Canciones: “Asomo la cabeza / por mi ventana, y veo / cómo quiere cortarla / la cuchilla del viento. / En esta guillotina / invisible, yo he puesto / la cabeza sin ojos / de todos mis deseos” (García Lorca 2008: I, 511). Son versos concebidos antes de la publicación del primer Manifiesto de Breton por parte de un poeta vanguardista que pudo parecer a algunos un surrealista ante litteram. ${ }^{8}$

Lo cierto es que Lorca, amigo de Salvador Dalí y de Luis Buñuel, estaba fascinado por el surrealismo, aunque su adhesión a esta escuela no se manifestó sino después del legendario homenaje a Góngora. Por otro lado, su entusiasmo por el genio lógico de Góngora fue pasajero, pues ya a finales de 1928 confesó su insatisfacción ante la estética del cordobés, declarando, en una entrevista, lo siguiente: “Inspiración, puro instinto, razón única del poeta. La poesía lógica me

8 Observa Gustav Siebenmann a propósito del neopopularismo lorquiano: "Lo importante ahí no es el procedimiento, no es la técnica, sino la arbitrariedad sorprendente, ya casi surrealista, de la invención de imágenes” (Siebenmann 1973: 297). 
es insoportable. Ya está bien la lección de Góngora” (García Lorca 1984: I, 19). ${ }^{9}$ A la actitud de quienes componían sus textos mediante el raciocinio contraponía su "vuelta a la inspiración". Un fragmento de su conferencia "Imaginación, inspiración, evasión”, dictada en el mes de octubre de 1928, de la que solo conocemos reseñas de prensa, muestra la misma postura:

La exaltación de Góngora que ha sentido toda la juventud poética española ha correspondido con la madurez del cubismo, pintura de raciocinio puro, austero de color y arabesco, que culminó en el castellanísimo Juan Gris. Pero en general pintores y poetas, después de la brisa pura del cubismo, vuelven los ojos "al puro instinto, a la creación virginal incontrolada, a la fuente fresquísima de la emoción directa, descansando bajo la fuerza irrefrenable de sus propias almas descubiertas" (García Lorca 1984: II, 26). ${ }^{10}$

En opinión de Lorca, al cubismo le sucedió el surrealismo, menos cerebral y más acorde con un genio intuitivo como el suyo. En tanto que poeta, sentía una fuerte atracción por este movimiento, porque el surrealismo fue, más que un estímulo, una justificación de su libertad creadora, por no decir una legitimación europea de lo que iba a realizar en sus obras posteriores al Romancero gitano.

El libro Poeta en Nueva York fue publicado dos veces en 1940, en ediciones diversas, ya que apareció primero en México y, tres semanas después, en edición bilingüe, en Nueva York (insisto en este detalle porque la edición Norton no aparece mencionada en las primeras bibliografías establecidas por Siebenmann, pero en 1979, en una reseña al libro de Eisenberg, "Poeta en Nueva York”. Historia y problemas de un texto de Lorca, ya hablaba de ambas ediciones). ${ }^{11}$ Poeta en Nueva York es una obra muy distinta de las precedentes, pero a su vez muy lorquiana por el hecho de plantear la situación del hombre frente a la angustia de los tiempos modernos. Como provinciano de formación humanista, trasplantado brutalmente a una de las mayores metrópolis del mundo, Lorca se encuentra con una civilización técnicamente avanzada pero anónima e inhumana, producto de un capitalismo salvaje que reduce al hombre a mero factor económico. $\mathrm{Su}$ yo lírico se siente "asesinado por el cielo" y amenazado por una ciudad monstruosa, poblada de "caimanes", "cocodrilos" y "sierpes", en la que "la sangre no tiene puertas" ni "el cielo, salida”. Existe una lista de dieciocho ilustraciones fotográficas que debían acompañar la publicación de Poeta en Nueva York, pero que no se reprodujeron en ninguna de las ediciones de 1940, dado que no constaban entre los materiales entregados por Lorca. Se conocen, sin embargo, las breves

9 Cit. por Maurer 1984.

10 Entre comillas se reproducen las citas textuales de la conferencia de Lorca.

11 Para más detalles, véase Siebenmann 1979. 
descripciones que el poeta hizo de ellas, y estas descripciones condicen con el contenido de sus poemas (Millán 1992: 54-59).

El drama, esta vez, consiste en el esfuerzo imposible del ser humano por realizarse, prisionero de un sistema de normas que ya no es el de la sociedad conservadora del Sur de Europa, sino el del capitalismo moderno. Recordemos que Lorca llega a Nueva York en el verano de 1929, tres meses antes del crack bursátil. Le parece, enseguida, que se hunde en una vorágine humana: en sus poemas, que son verdaderas pesadillas, imagina una metrópoli de muertos vivientes, fantasmas insomnes, autómatas, de muchedumbres que vomitan y orinan, de masas alienadas y alienantes. Expresa estas alucinaciones en versos libres, al estilo de Walt Whitman, entregándose a un río desbordante de imágenes, por lo general poco estructuradas. En ciertos textos se comprende que detrás de esa proliferación de imágenes hay un pensamiento crítico que podría articularse racionalmente, y entonces su poesía corre el riesgo de caer en la enumeración gratuita, en la retórica. En otros poemas, sin embargo, como "El rey de Harlem", su imaginación se desata, abriendo paso a sus fantasías más atrevidas. ¿Quién es este rey de los negros? Se trata de una criatura imaginaria, especie de monstruo para niños, un viejo con la piel "cubierta de setas" y con "las barbas que llegan al mar”, un "rey prisionero" vestido con "un traje de conserje”, pero también un fantasma protector, un Moisés que "canta con la muchedumbre”, adoptando el papel de libertador de su pueblo (García Lorca 2008: II, 252-256). De él se dice incluso, en un lenguaje que llama la atención por sus fantasías sádicas, que "con una cuchara de palo" "arranca los ojos a los cocodrilos" y "golpea el trasero de los monos", mientras "los niños" "machacan pequeñas ardillas / con un rubor de frenesí manchado” (Koppenfels 2000: 219). Es este un Lorca insólito, fantaseador grotesco, que merecería un análisis detallado por parte de un especialista. Creo, sin embargo, haber mostrado con este ejemplo que existen afinidades profundas entre la poesía de este Lorca y el surrealismo europeo de matriz freudiana.

\section{Acerca de la recepción de Lorca en Alemania}

No quiero poner fin a estas consideraciones sin señalar que una parte importante de los estudios lorquianos de Gustav Siebenmann se refiere a la historia de la recepción de la obra de Lorca, tanto en los países de lengua alemana como en América Latina. Uno de sus trabajos más significativos al respecto, "La recepción de Federico García Lorca en los países germánicos. Crónica de una distorsión”, aparecido en el Homenaje al profesor Antonio Vilanova, en 1989, contempla las dos fases de este proceso: la primera, aún incierta, caracterizada por una serie de malentendidos; y la segunda, de nivel más académico, gracias a las contribucio- 
nes de Horst Baader, Hugo Friedrich, Harald Weinrich, Werner Krauss y el propio Siebenmann. La versión alemana de este estudio, acompañada de una bibliografía de los escritos sobre Lorca aparecidos en el mundo germano entre 1927 y 1987 , puede leerse en el volumen Essays zur spanischen Literatur (Siebenmann 1989: 250-254).

A partir de los años sesenta, por tanto, surgieron trabajos de gran calidad, como la tesis doctoral del suizo Christoph Eich, publicada en Gredos bajo el título Federico García Lorca, poeta de la intensidad (1958), y las numerosas traducciones de la obra poética y dramática, así como de los escritos en prosa. Según hemos dicho, Siebenmann habla, a propósito de los comienzos de la recepción, de una serie de interpretaciones aberrantes, en cuanto el público alemán comenzó asociando el nombre de Lorca a los conocidos lugares comunes de la España pintoresca y del andalucismo transmitidos por la literatura y la música del siglo XIX. Los primeros juicios críticos sobre Lorca, asimismo, fueron o parciales (como el de Fernández-Montesinos, profesor en Hamburgo, quien, en 1927, hablaba de un Lorca "poeta inculto, carente de formación literaria"), o bien condicionados por el clima ideológico de entonces (Hans Jeschke, por ejemplo, en su Handbuch der Literaturwissenschaft, de 1935, denunciaba “el arte decadente" del granadino), de modo que no pudo formarse una crítica seria, atenta al estilo novedoso de su obra. Pero Siebenmann polemiza, sobre todo, con el filósofo de la cultura Jean Gebser, quien durante su estancia en España en los años treinta había conocido personalmente a Federico García Lorca (y a Luis Cernuda, con quien llegó a traducir algunos poemas de Hölderlin). Aunque admite que Gebser es un excelente traductor, disiente claramente de su interpretación psicoanalítica de la personalidad del poeta. Gebser, en su libro Lorca y el reino de las madres (1949), sostiene de hecho su tesis de que Lorca fue el típico niño crecido en un hogar de mujeres, educado por su madre, su anciana tía y su abuela, a la vez que tenía un padre severo y hostil a su vocación literaria. Esta peculiar condición explicaría su interés por las canciones para niños, la naturaleza de Andalucía y la sufrida voz popular, en que Gebser reconoce las figuras arquetípicas de lo materno. Por la misma razón, según este crítico, Lorca recurría preferentemente a las imágenes de la noche, de la luna, de los toros, de la sangre, etc., e incluso en el drama La casa de Bernarda Alba se manifestaría “aquel reino de las madres, en que la vida es muerte, y la muerte vida”. Ante este simbolismo más bien simplista, Siebenmann toma sus distancias, y no es difícil darle la razón.

Otro personaje problemático de esta “crónica de una distorsión” es el principal traductor de la obra de Lorca, el emigrante alemán Enrique Beck, quien, huyendo del régimen nazi, se había refugiado primero en Suiza y después en España, donde permaneció cinco años, hasta 1938. Beck comenzó a traducir a Lorca ya durante la Guerra Civil: en 1938 publicó en Zúrich sus Zigeunerromanzen. 
Diez años más tarde dio a conocer una selección de poemas (Gedichte, Stuttgart 1948) y a continuación se ocupó del teatro, editando en alemán un drama tras otro. Mientras tanto había obtenido del hermano del poeta, Francisco García Lorca, el derecho para traducir todos los textos de Lorca que fueron apareciendo, llegando a detentar prácticamente el monopolio de la traducción de Lorca en los países de lengua alemana. Siebenmann pertenece a quienes han criticado severamente el estilo de este traductor, pues le reprocha el uso de un lenguaje abundante en preciosismos, formas anticuadas y recursos cuestionables y lo tacha de traductor obstinado. En su conmemoración para los cien años del nacimiento del poeta, no deja de recordar el sarcástico comentario de Harald Weinrich, según quien "el que hubiese leído a Lorca apenas en la traducción de Beck, aún no conocería a este poeta" (Siebenmann 1998: 67). Recordemos que el propio Siebenmann, autor de una célebre antología titulada Spanische Lyrik des 20. Jahrhunderts, ${ }^{12}$ dio a la luz una selección de poemas traducidos de Federico García Lorca: Poemas-Gedichte: Spanisch-Deutsch (Reclam, 2007).

Para terminar, voy a reproducir la "Baladilla de los tres ríos", primero en su forma original, después en las versiones alemanas de Jean Gebser (1936) y de Enrique Beck (1948). De este modo, el lector podrá darse cuenta del distinto modo de traducir de estos autores y también del juicio competente de nuestro colega, quien no oculta su preferencia por la versión más antigua de Gebser. Limitándome a unas pocas observaciones al respecto, concuerdo naturalmente con Siebenmann cuando opina que Enrique Beck traduce algunas veces bastante mal, como cuando, a propósito de las "torrecillas muertas de Granada”, habla de las "Türmchen, die schon bei den Teichen enden”; y cuando recurre a expresiones arcaizantes y ostentosamente líricas que falsean la intención poética original. Así, Beck vierte el verbo llano "bajar”, dicho de los ríos de Granada, con el dramático verbo "sich stürzen”; traduce el sintagma corriente “¿quién dirá que?” por el rebuscado "wer wohl sagt” y, de modo análogo, la sencilla queja “ay, amor / que se fue por el aire” por "Liebe, in Lüften vergangen!”. Son opciones de gusto discutible, tanto más cuanto que la comparación con las soluciones de Gebser muestra que este traductor supo mantener la leve sencillez del Poema del cante jondo. Sigue aquí el cotejo de las dos traducciones, a las que anteponemos el poema en su lengua original:

12 En su antología de la poesía española del siglo XX, Siebenmann reproduce siete poemas de Lorca, cuatro de Jorge Guillén y siete de Cernuda. Las traducciones de los poemas lorquianos son, con una única excepción, las de Enrique Beck (Siebenmann/López 1985: 128-147). 


\section{Baladilla de los tres ríos}

El río Guadalquivir va entre naranjos y olivos. Los dos ríos de Granada bajan de la nieve al trigo.

¡Ay, amor

que se fue y no vino!

El río Guadalquivir tiene las barbas granates. Los dos ríos de Granada, uno llanto y otro sangre.

iAy amor

que se fue por el aire!

Para los barcos de vela

Sevilla tiene un camino;

Por el agua de Granada

solo reman los suspiros.

iAy, amor

que se fue y no vino!

Kleine Ballade von den drei Flüssen

Guadalquivir -

an Orangen und Oliven vorüber.

Die beiden Flüsse Granadas

fließen vom Schnee zum Weizen hinab.

Ach der Liebe,

die ging und nie wiederkam!

Der Guadalquivir

hat granatrotes Haar.

Die beiden Flüsse Granadas -

der eine Weinen, der andere Blut.

Ach der Liebe,

die im Wind verging!

Für seine Segel

hat Sevilla einen Weg,
Guadalquivir, alta torre $\mathrm{y}$ viento en los naranjales. Dauro y Genil, torrecillas muertas sobre los estanques

iAy amor

que se fue por el aire!

¡Quién dirá que el agua lleva un fuego fatuo de gritos!

¡Ay, amor

que se fue y no vino!

Lleva azahar, lleva olivas, Andalucía, a tus mares.

¡Ay, amor

que se fue por el aire!

\section{Kleine Ballade von den drei Flüssen}

Durch Oliven und Orangen

strömet der Guadalquivir.

Die zwei Flüsse von Granada

stürzen sich vom Schnee zum

Weizen.

O Liebe,

die ging und nicht kam!

Der Guadalquivir hat Bärte

von der Farbe des Granates.

Aber Klage sind und Blut

die zwei Flüsse von Granada.

O Liebe,

in Lüften vergangen!

Einen Weg für Segelschiffe

hat Sevilla. Doch Granada - 
auf den Wassern Granadas

rudern nur Seufzer.

Ach der Liebe,

die ging und nie wiederkam.

Guadalquivir, hoher Turm, und Wind in den Orangenhainen! Darro und Genil, tote Türmchen über den Teichen.

Ach der Liebe, die im Wind verging!

Wer wagt zu sagen, das Wasser trüge ein Irrlicht aus Schreien -

Ach der Liebe, die ging und nie wiederkam!

Es trägt Orangenblüten und Oliven den andalusischen Meeren zu.

Ach der Liebe, die im Wind verging!

(Gebser 1949: 44-46) auf den Wassern von Granada rudern einsam nur die Seufzer.

O Liebe,

die ging und nicht kam!

Wind im Haine der Orangen, Hoher Turm, Guadalquivir. Dauro und Genil sind Türmchen, die schon bei den Teichen enden.

O Liebe, in Lüften vergangen!

Wer wohl sagt, dass Wasser trüge Schreie, die wie Irrlichter zucken!

O Liebe, die ging und nicht kam!

Nein, es trägt Orangenblüten, trägt Oliven, Andalusien, deinen beiden Meeren zu.

O Liebe, in Lüften vergangen!

(Beck en García Lorca 1982: I, 37-38).

\section{Bibliografía}

Diego, Gerardo (ed.) (1968): Poesía española contemporánea (1901-1934), 4a ed. Madrid: Taurus.

García Lorca, Federico (1973): Obras completas, ed. Arturo del Hoyo, prólogo Jorge Guillén, 18‥ ed. Madrid: Aguilar, vols. I y II.

- (1982): Werke in drei Bänden, ed. y trad. Enrique Beck, Frankfurt a. M.: Insel, vol. I.

- (1984): Conferencias, ed. Christopher Maurer, Madrid: Alianza, vols. I y II.

- (2000): Dichter in New York, trad. Martin von Koppenfels, Frankfurt a. M.: Suhrkamp.

- (2007): Poemas-Gedichte, ed. y trad. Gustav Siebenmann, Stuttgart: Reclam.

- (2008): Obra completa, ed. Miguel García-Posada, Madrid: Akal.

García-Posada, Miguel (2008): “Introducción general”, en: García Lorca, Federico: Obra completa, ed. Miguel García-Posada, Madrid: Akal, vol. I, pp. 11-161.

Gebser, Jean (1949): Lorca oder das Reich der Mütter, Stuttgart: Deutsche Verlags-Anstalt. Guillén, Jorge (1973 $\left.{ }^{18}\right)$ : “Federico en persona”, en: García Lorca, Federico: Obras completas, ed. Miguel García-Posada, Madrid: Akal, vol. I, pp. XV-LXXXI. 
Koppenfels, Martin von (2000): “Nachwort”, en: García Lorca, Federico: Dichter in New York, Frankfurt a.M.: Suhrkamp, pp. 209-230.

Maurer, Christopher (ed.) (1973): García Lorca, Federico: Conferencias, Madrid: Alianza vols. I y II.

Millán, María Clementa (ed.) (1992): “Introducción”, en: García Lorca, Federico: Poeta en Nueva York. Madrid: Cátedra, pp. 11-98.

Rivero Iglesias, Carmen (ed.) (2014): Spanische Literaturgeschichte. Eine kommentierte Anthologie, Paderborn: Wilhelm Fink.

Rudin, Ernst (1997): Übersetzung und Rezension García Lorcas im deutschen Sprachraum, Kassel: Reichenberger.

Siebenmann, Gustav (1965): Die moderne Lyrik in Spanien. Ein Beitrag zu ihrer Stilgeschichte, Stuttgart: Kohlhammer.

- (1973): Los estilos poéticos en España desde 1900, trad. Ángel San Miguel, Madrid: Gredos.

- (1979): “Reseña” al libro de Daniel Eisenberg, Poeta en Nueva York. Historia y problemas de un texto de Lorca, ZRPH 95, pp. 702-704.

- (1989): Essays zur spanischen Literatur, Madrid/Frankfurt a. M.: Iberoamericana/Vervuert.

- (1998): "Weil er ein großer Dichter war. Zum 100. Geburtstag von Federico García Lorca”, Neue Zürcher Zeitung, 6 y 7 de junio, núm. 128, p. 67.

- (ed.) (2007): Poemas-Gedichte, Stuttgart: Reclam.

Siebenmann, Gustav/López, José Manuel (1985): Spanische Lyrik des 20. Jahrhunderts, Stuttgart: Reclam. 